\title{
Some Curcumin Isomers and Their Enol Tautomers - A DFT Treatment
}

\section{Lemi Türker}

Department of Chemistry, Middle East Technical University, Üniversiteler, Eskişehir Yolu No: 1, 06800 Çankaya/Ankara, Turkey; e-mail: lturker@gmail.com; lturker@metu.edu.tr

\begin{abstract}
Curcumin is a well known natural product having some health benefits. In the present study, within the constraints of density functional theory (at the level of B3LYP/6$31 \mathrm{G}(\mathrm{d}, \mathrm{p})$ ), some configurational isomers of curcumin and their keto-enol tautomers have been investigated. Some quantum chemical, QSAR and spectral data of them have been obtained and discussed.
\end{abstract}

\section{Introduction}

Curcumin is a natural product which aids in the management of oxidative and inflammatory conditions, metabolic syndrome, arthritis, anxiety, and hyperlipidemia. It is found in Turmeric which is a rhizomatous herbaceous perennial plant (Curcuma longa) of the ginger family $[1,2]$. Curcumin may also help in the management of exerciseinduced inflammation and muscle soreness, thus enhancing recovery and performance in active people [3, 4]. Its anticancer potential was investigated [5-9]. In addition, a relatively low dose of the complex can provide health benefits for people that do not have diagnosed health conditions $[3,4,10,11]$. Most of these benefits can be attributed to its antioxidant and anti-inflammatory effects. Ingesting curcumin by itself does not lead to the associated health benefits due to its poor bioavailability [3, 12, 13].

Keywords and phrases: Curcumin, diferuloylmethane, tautomerism, natural product, density functional.

Copyright (C) 2020 Lemi Türker. This is an open access article distributed under the Creative Commons Attribution License, which permits unrestricted use, distribution, and reproduction in any medium, provided the original work is properly cited. 


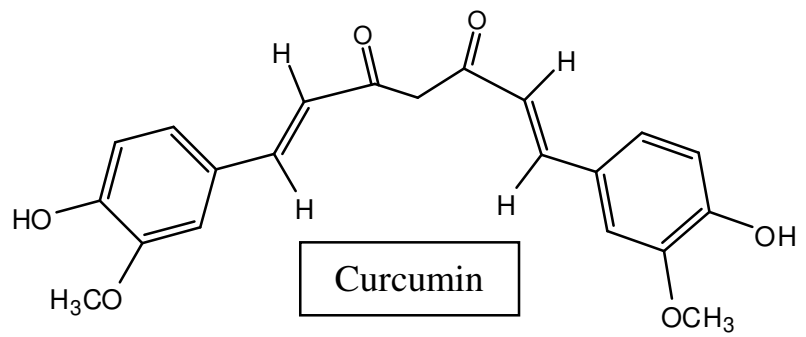

Some Curcumin-like molecules have also been investigated [14, 15]. Curcumin (1,7bis(4-hydroxy-3-methoxyphenyl)-1,6-heptadiene-3,5-dione), also called diferuloylmethane, is the main natural polyphenol found in the rhizome of Curcuma longa (turmeric) and in others Curcuma spp. [5]. Curcuma longa has been traditionally used in Asian countries as a medical herb due to its antioxidant, anti-inflammatory [16], antimutagenic, antimicrobial [17], and anticancer properties [2, 18]. Priyadarsini et al. studied the role of phenolic $\mathrm{O}-\mathrm{H}$ and methylene hydrogen on the free radical reactions and antioxidant activity of curcumin [19].

\section{Method of Calculation}

Structure optimizations leading to energy minima were initially achieved by using MM2 method which was followed by semi-empirical PM3 self-consistent fields molecular orbital (SCF MO) method [20, 21] at the restricted level [22, 23]. Subsequent optimizations were achieved at Hartree-Fock level by using various basis sets. Then, the optimizations were managed within the framework of density functional theory (DFT) using B3LYP functional $[24,25]$ at the level of $6-31 \mathrm{G}(\mathrm{d}, \mathrm{p})$. The exchange term of B3LYP consists of hybrid Hartree-Fock and local spin density (LSD) exchange functions with Becke's gradient correlation to LSD exchange $[25,26]$. The correlation term of B3LYP consists of the Vosko, Wilk, Nusair (VWN3) local correlation functional [27] and Lee, Yang, Parr (LYP) correlation correction functional [28]. The present vibrational analyses have been also done at the same level of calculations which had been performed for the optimizations. The total electronic energies (E) are corrected for the zero point vibrational energy $(\mathrm{ZPE})$ to yield $\mathrm{E}_{\mathrm{C}}$ values. The normal mode analysis for each structure yielded no imaginary frequencies for the $3 N-6$ vibrational degrees of freedom, where $N$ is the number of atoms in the system. Thus, the structure of each molecule corresponds to at least a local minimum on the potential energy surface. All these calculations were done by using the Spartan 06 package program [29]. 


\section{Results and Discussion}

\subsection{Diketo isomers of curcumin}

The molecule, in the literature known as curcumin whose structure shown above, possesses two olefinic double bonds having trans configuration and two keto groups ( $\beta$-dicarbonyl system) along its backbone. Presently, firstly configurational isomers of curcumin, based on the cisness and transness of these double bonds are considered. Curcumin itself is labeled as curcumin trans-trans and its configurational isomers as cistrans curcumin and cis-cis curcumin. Presently the configurational varieties of the isomers are labelled as cis or trans rather than $E$ and $Z$ assignments for the sake of easier visualization. Figure 1 shows the optimized structures of these isomers as well as
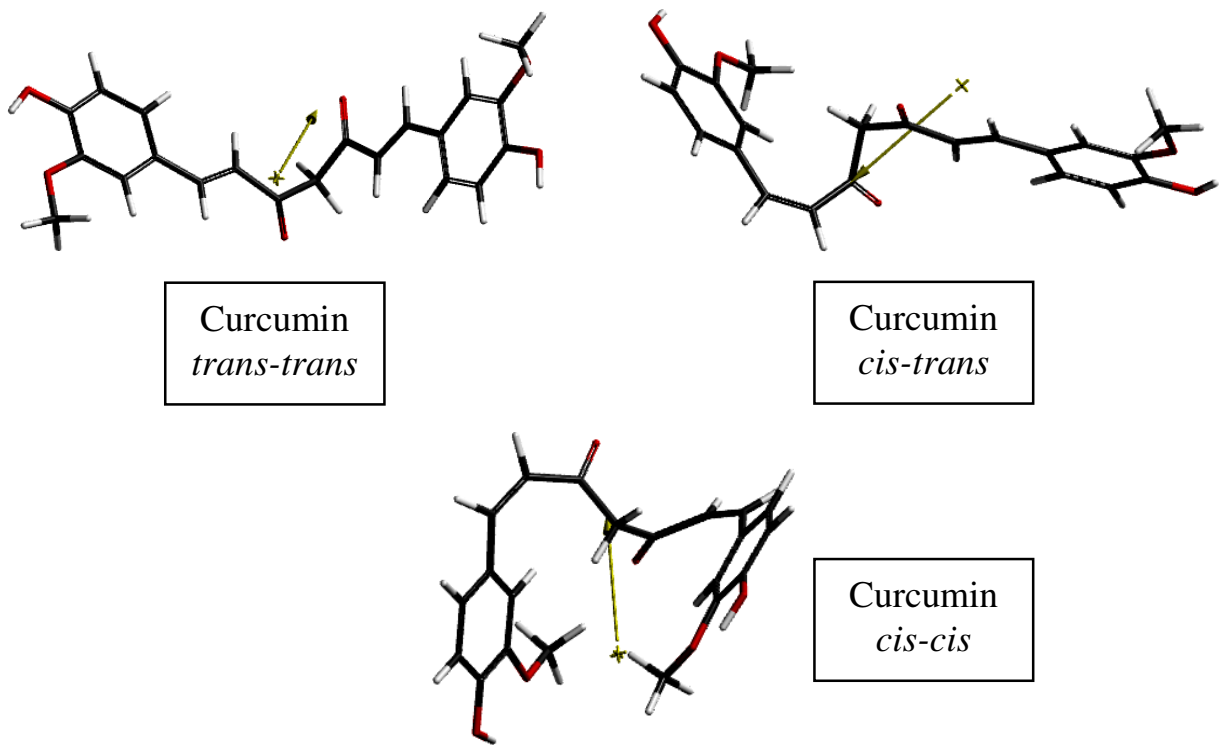

Figure 1. Optimized diketo structures of present concern.

the direction of the dipole moment vectors. As seen in the figure, the trans-trans and cistrans isomers have more or less straight structures whereas the cis-cis isomer is curled one. Table 1 shows some properties of these isomeric structures. The trans-trans form (curcumin itself) has the highest dipole moment among the all, whereas the cis-trans possesses the lowest. On the other hand, all these diketo isomers have the same Log P values, comparable polarizabilities and ovality values however those values for the ciscis isomer are the smallest ones. 
Table 1. Some properties of the diketo isomers of curcumin.

\begin{tabular}{lcccccc}
\hline Structure & $\begin{array}{c}\text { Dipole } \\
\text { moment } \\
\text { (debye) }\end{array}$ & $\begin{array}{c}\text { Area } \\
\left(\mathbf{\AA}^{\mathbf{2}}\right)\end{array}$ & $\begin{array}{c}\text { Volume } \\
\left.\mathbf{( \mathbf { \AA }}^{\mathbf{3}}\right)\end{array}$ & Ovality & $\log \mathbf{P}$ & Polarizability \\
cis-cis & 3.08 & 391.43 & 374.78 & 1.56 & 4.23 & 70.84 \\
cis-trans & 1.87 & 399.51 & 375.80 & 1.59 & 4.23 & 70.96 \\
trans-trans & 6.23 & 407.17 & 377.13 & 1.61 & 4.23 & 71.10 \\
\hline
\end{tabular}

Figure 2 shows the calculated IR spectra of these isomers. The phenolic O-H stretchings in these structures occur at about $3700 \mathrm{~cm}^{-1}$. In the cis-cis and trans-trans cases distinct stretchings are obtained for the $\mathrm{O}-\mathrm{H}$ groups present. The $\mathrm{C}=\mathrm{O}$ stretchings happen between $1700-1750 \mathrm{~cm}^{-1}$.
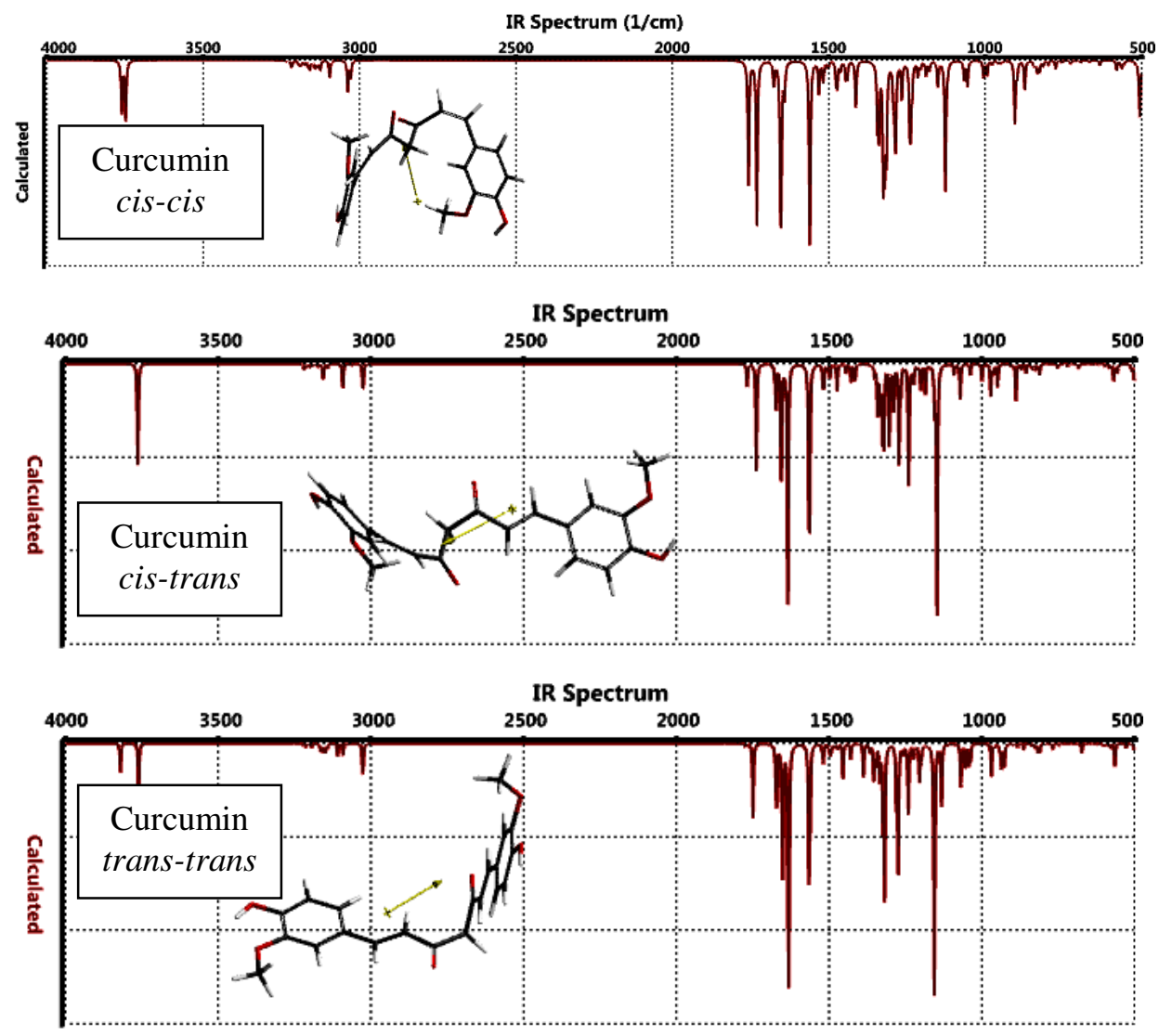

Figure 2. Calculated IR spectra of the diketo isomers of curcumin. 
Table 2 shows some energies of the diketo isomers of curcumin where E, ZPE and $\mathrm{E}_{\mathrm{C}}$ stand for the total electronic energy, zero point vibrational energy and the corrected total electronic energy, respectively. Based on the $\mathrm{E}_{\mathrm{C}}$ values the electronic stability order of these isomers is trans-trans (curcumin) $>$ cis-trans $>$ cis-cis. This order occurs because various structural and electronic effects collectively operate. In these huge molecules various attractive and/or repulsive forces should be present. Note that the keto groups present are electron attractors mesomerically and inductively. The phenolic $\mathrm{OH}$ groups and $\mathrm{OCH}_{3}$ groups are mesomerically donate electrons but the oxygen atom of them is inductively electron attractor. All these conjugative effects combined with the conformational varieties of the groups determine the various properties tabulated in Tables 1 and 2.

Table 2. Some energies of the diketo isomers of curcumin considered.

\begin{tabular}{lccc}
\hline Structure & $\mathbf{E}$ & $\mathbf{Z P E}$ & $\mathbf{E}_{\mathbf{C}}$ \\
\hline cis-cis & -3317536.71 & 973.57 & -3316563.14 \\
cis-trans & -3317560.38 & 973.94 & -3316586.44 \\
trans-trans & -3317570.70 & 972.16 & -3316598.54 \\
\hline
\end{tabular}

Energies in $\mathrm{kJ} / \mathrm{mol}$.

Figure 3 displays some molecular orbital energy levels of the diketo isomers. All have closely spaced HOMO and next HOMO (NHOMO) energy levels. As for LUMO and next LUMO (NLUMO) levels, they are closely spaced in the cis-cis isomer but gradually they are further and further spaced in the cis-trans and trans-trans isomers.

Table 3 tabulates the HOMO, LUMO energies and the interfrontier molecular orbital (FMO) energy gaps $(\Delta \varepsilon)$ for these isomers. The order of the HOMO energies is ciscis < trans-trans < cis-trans whereas the LUMO energy order is trans-trans < cistrans $<$ cis-cis. Note that generally electron attractors lower both the HOMO and LUMO energy levels in contrast to electron donors which raise up both the HOMO and LUMO energy levels (of course at unequal extents) [30]. Consequently the $\Delta \varepsilon$ values follow the order of trans-trans < cis-trans < cis-cis as the order of LUMO energies. This order results in some bathochromic effect in the calculated UV-Vis spectra which are shown in Figure 4. 

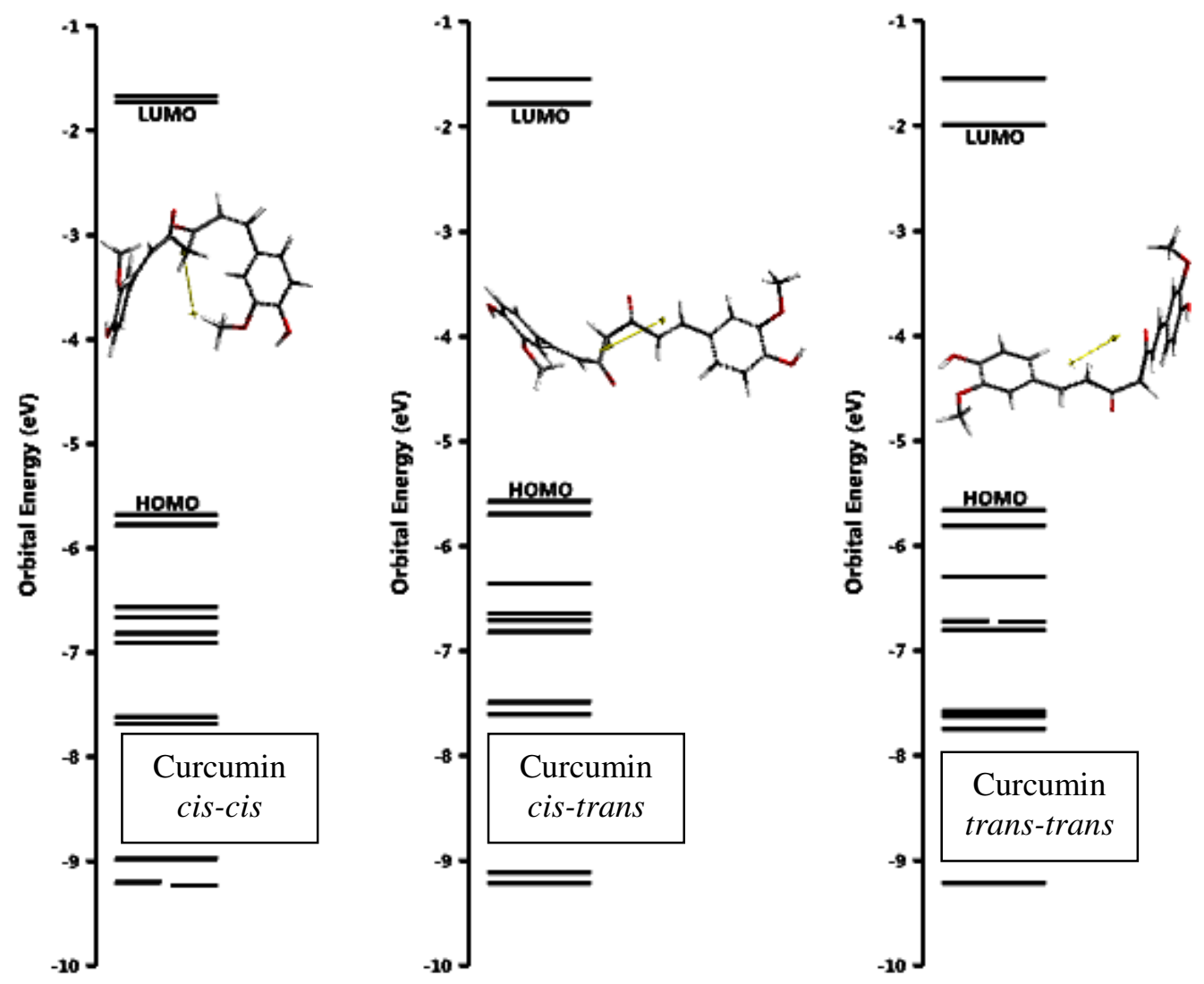

Figure 3. Some molecular orbital energies of the diketo isomers of curcumin.

Table 3. The HOMO, LUMO energies and the FMO energy gaps $(\Delta \varepsilon)$ of the diketo structures considered.

\begin{tabular}{lccc}
\hline Structure & HOMO & LUMO & $\Delta \boldsymbol{\varepsilon}$ \\
\hline cis-cis & -548.07 & -166.73 & 381.34 \\
cis-trans & -537.75 & -171.85 & 365.90 \\
trans-trans & -545.86 & -192.03 & 353.83 \\
\hline
\end{tabular}

Energies in $\mathrm{kJ} / \mathrm{mol}$. 

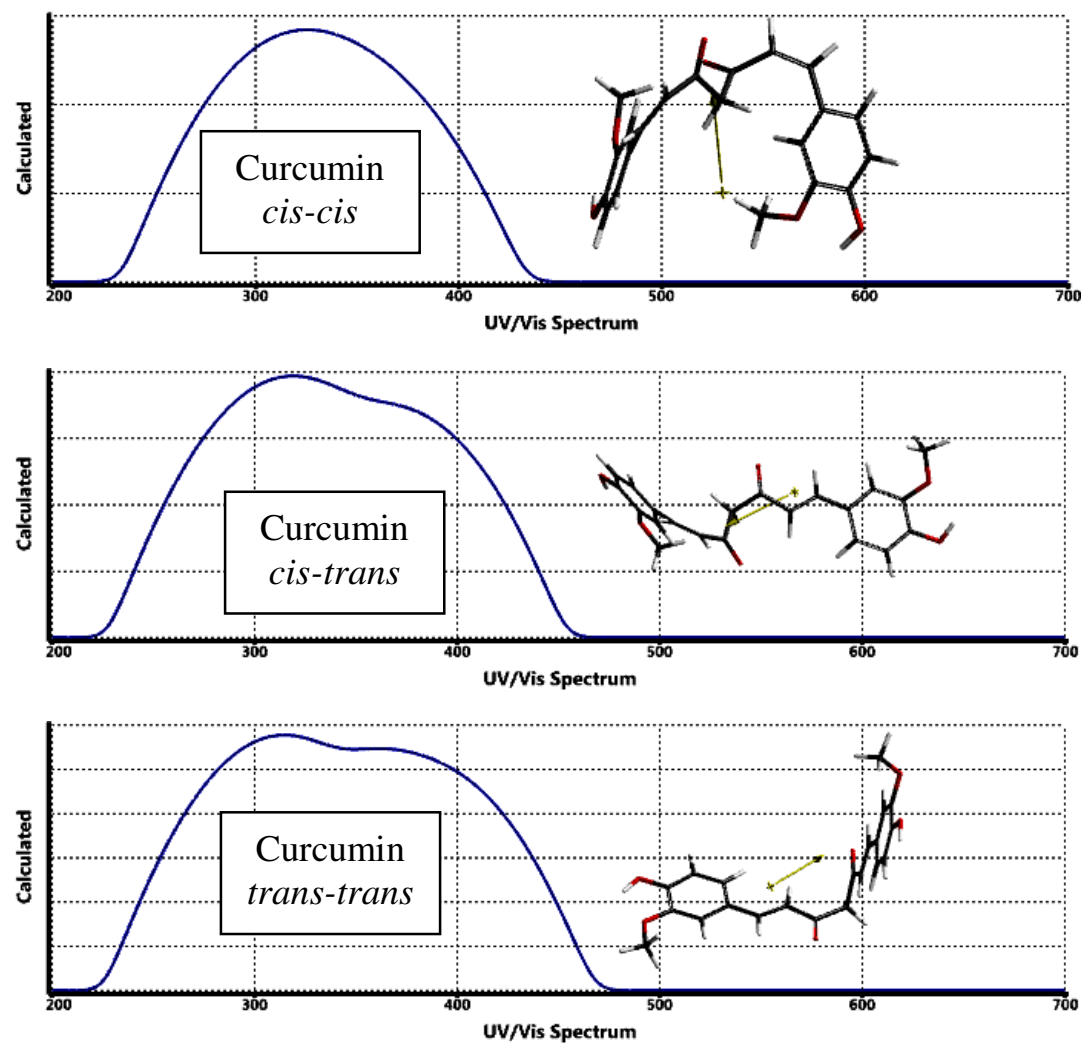

Figure 4. Calculated UV - Vis spectra of the diketo isomers of curcumin.

\subsection{The 1,3-keto-enol tautomers}

Curcumin and its diketo isomers considered above are $\beta$-dicarbonyl structures. The methylenic hydrogens in between the keto groups of those structures are capable of undergoing 1-3-type proton tautomerism. So various enols may arise which are isomeric and also isomeric with the diketo structures mentioned before. The enolization process considered increases the extended conjugation in these structures. The enolic - $\mathrm{OH}$ in these structures might be on the opposite side of the remaining carbonyl group (enol-1 series) or on the same side (enol-2 series) so that hydrogen bonding is possible. In the case of cis-trans tautomers, lower case letters $\mathrm{c}$ and $\mathrm{t}$ at the end of their labels (such as cis-trans-enol-1c or cis-trans-enol-1t) stand for position of the enolic $\mathrm{OH}$ group whether it is on the same side of the structure with the cis or trans olefinic moiety (see Figure 5).

Figure 5 shows the optimized structures of the enol forms of the tautomers and their 

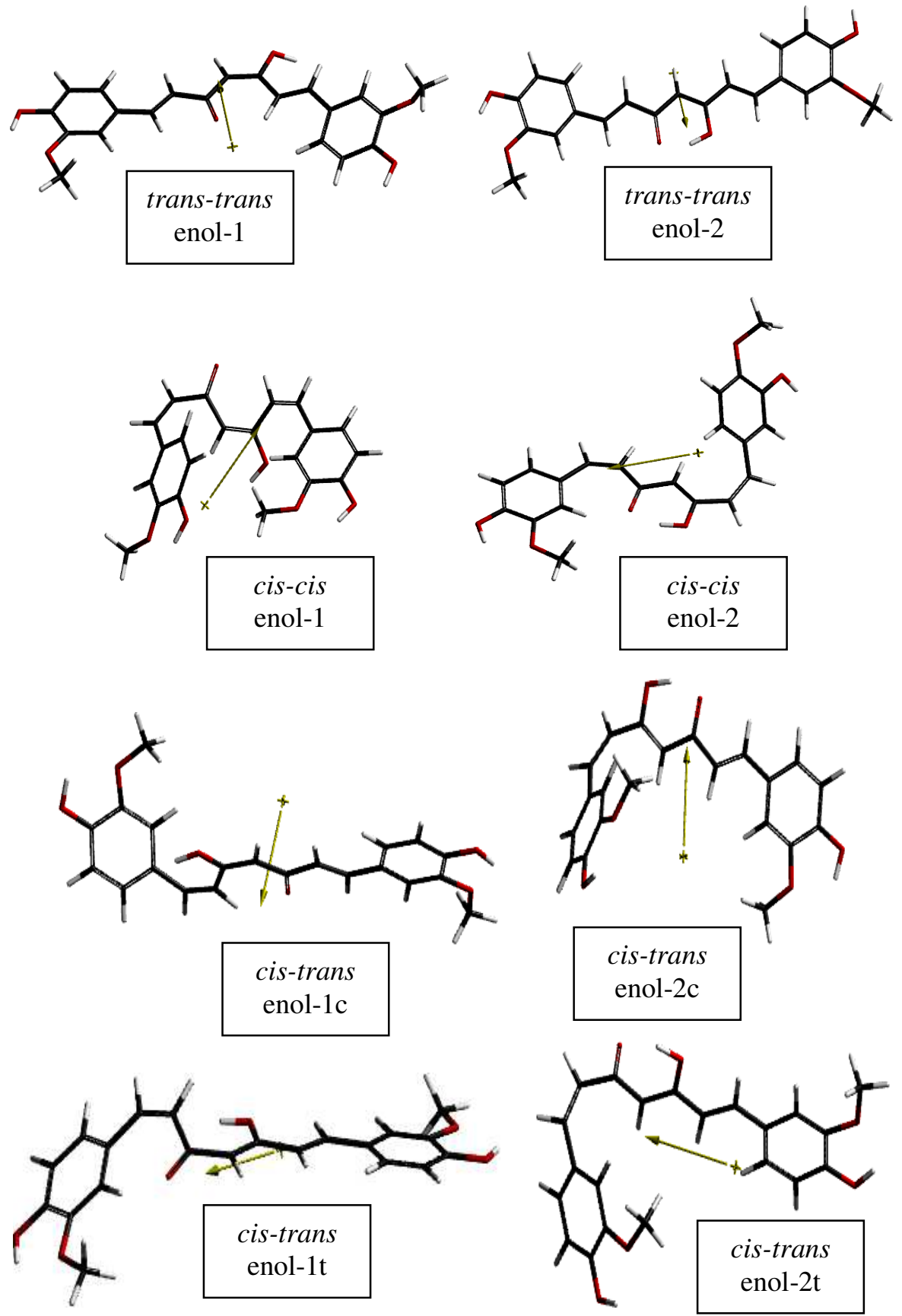

Figure 5. Optimized structures of the tautomers considered. 
direction of the dipole moment vectors as well. Table 4 shows some properties of the enols considered. The data indicate that in the case of cis-cis and trans-trans forms, the enol-1 series have higher dipole moment values than their enol-2 counterparts, contrary to the cis-trans-enol series for which the enol-2 series possess higher dipole moments than their enol-1 series. Note that the enol-2 series can form hydrogen bonding via sixmembered ring formation which affects the charge distribution highly different than the enol-1 series.

Also note that through the enolization process some of these tautomers, having the same olefinic configuration, are interconvertible to each other, such as cis-cis-enol-1 and cis-cis-enol-2.

Table 4. Some properties of the tautomers of concern.

\begin{tabular}{lcccccc}
\hline Structure & $\begin{array}{c}\text { Dipole } \\
\text { moment } \\
(\mathbf{d e b y e})\end{array}$ & $\begin{array}{c}\text { Area } \\
\left(\mathbf{\AA}^{\mathbf{2}}\right)\end{array}$ & $\begin{array}{c}\text { Volume } \\
\left(\mathbf{\AA}^{\mathbf{3}}\right)\end{array}$ & Ovality & Log P & Polarizability \\
\hline cis-cis-enol-1 & 7.52 & 395.32 & 374.98 & 1.57 & 3.43 & 70.98 \\
cis-cis-enol-2 & 3.98 & 394.48 & 374.22 & 1.57 & 3.43 & 70.97 \\
trans-trans-enol-1 & 4.08 & 404.01 & 376.52 & 1.60 & 3.43 & 71.14 \\
trans-trans-enol-2 & 2.62 & 403.09 & 375.40 & 1.60 & 3.43 & 71.05 \\
cis-trans-enol-1c & 1.51 & 398.49 & 375.11 & 1.58 & 3.43 & 71.01 \\
cis-trans-enol-2c & 4.66 & 396.75 & 374.20 & 1.58 & 3.43 & 70.94 \\
cis-trans-enol-1t & 4.03 & 398.14 & 374.68 & 1.58 & 3.43 & 70.98 \\
cis-trans-enol-2t & 4.24 & 396.46 & 374.12 & 1.58 & 3.43 & 70.94 \\
\hline
\end{tabular}

Table 5 shows the $\mathrm{E}, \mathrm{ZPE}$ and $\mathrm{E}_{\mathrm{C}}$ values of the tautomers considered. The data reveal that in all the cases, enol-2 series are more stable than that of enol-1 series of tautomers. The trans-trans-enol-2 is the most and cis-cis-enol-1 is the least stable ones. On the other hand, comparison of the data in Tables 2 and 5 indicate that some of the enol structures are more stable than all of the keto forms considered. For instance, transtrans-enol-2 is more stable than its diketo form trans-trans which is curcumin itself. 
Table 5. Some energies of the tautomeric structures considered.

\begin{tabular}{lccc}
\hline Structure & $\mathbf{E}$ & $\mathbf{Z P E}$ & $\mathbf{E}_{\mathbf{C}}$ \\
\hline cis-cis-enol-1 & -3317508.07 & 974.65 & -3316533.42 \\
cis-cis-enol-2 & -3317553.71 & 975.46 & -3316578.25 \\
trans-trans-enol-1 & -3317541.60 & 973.38 & -3316568.22 \\
trans-trans-enol-2 & -3317600.87 & 972.68 & -3316628.19 \\
cis-trans-enol-1c & -3317552.84 & 976.00 & -3316576.84 \\
cis-trans-enol-2c & -3317595.69 & 975.67 & -3316620.02 \\
cis-trans-enol-1t & -3317554.53 & 976.45 & -3316578.08 \\
cis-trans-enol-2t & -3317595.87 & 975.39 & -3316620.48 \\
\hline
\end{tabular}

Energies in $\mathrm{kJ} / \mathrm{mol}$.

Table 6 includes some stretching frequencies of the groups present in the tautomers considered. One noticeable point in the data is that $\mathrm{O}-\mathrm{H}$ stretching frequency of the enols of series- 2 occurs at lower frequencies as compared to their enol-1 counterparts. This is due to the possible hydrogen bonding in the series- 2 enols.

Table 6. Some calculated IR stretchings frequencies of the tautomers considered.

\begin{tabular}{lccc}
\hline Structure & $\mathbf{C}=\mathbf{O}$ & H-O (enolic) & H-O (phenolic) \\
\hline cis-cis-enol-1 & 1717,1674 & 3802 & 3764,3758 \\
cis-cis-enol-2 & 1658,1655 & 2838 & 3826,3756 \\
trans-trans-enol-1 & 1726,1669 & 3813 & 3822,3765 \\
trans-trans-enol-2 & 1705,1609 & 2769 & 3823,3760 \\
cis-trans-enol-1c & 1667,1651 & 3768 & 3763,3760 \\
cis-trans-enol-2c & 1670,1612 & 2784 & 3763,3758 \\
cis-trans-enol-1t & 1704,1684 & 3682 & 3763,3752 \\
cis-trans-enol-2t & 1644,1619 & 2813 & 3762,3762 \\
\hline
\end{tabular}

Frequencies in $\mathrm{cm}^{-1}$. 
Table 7 shows $\lambda_{\max }$ values of the tautomers. The tautomers mostly have two $\lambda_{\max }$ values and mostly they are in the UV region.

Table 7 . Calculated $\lambda_{\max }$ values (nm) of the tautomers considered.

\begin{tabular}{lc}
\hline Structure & \\
\hline cis-cis-enol-1 & $399.00,302.07$ \\
cis-cis-enol-2 & $419.63,316.54$ \\
trans-trans-enol-1 & $401.90,308.82$ \\
trans-trans-enol-2 & $398.23,311.25$ \\
cis-trans-enol-1c & $397.74,303.36$ \\
cis-trans-enol-2c & $410.23,362.83,297.61$ \\
cis-trans-enol-1t & $399.48,300.58$ \\
cis-trans-enol-2t & $398.23,311.25$ \\
\hline
\end{tabular}

Table 8 shows the HOMO, LUMO energies and $\Delta \varepsilon$ values of the tautomers. The HOMO energies of series- 2 enols are lower than series- 1 counterparts in each case. The Table 8. The HOMO, LUMO energies and the FMO energy gaps $(\Delta \varepsilon)$ of the tautomeric structures considered.

\begin{tabular}{lccc}
\hline Structure & HOMO & LUMO & $\Delta \boldsymbol{\varepsilon}$ \\
\hline cis-cis-enol-1 & -507.14 & -174.90 & 332.24 \\
cis-cis-enol-2 & -517.90 & -208.77 & 309.13 \\
trans-trans-enol-1 & -514.72 & -196.50 & 318.22 \\
trans-trans-enol-2 & -516.52 & -199.43 & 317.09 \\
cis-trans-enol-1c & -517.09 & -194.10 & 322.99 \\
cis-trans-enol-2c & -525.63 & -203.64 & 321.99 \\
cis-trans-enol-1t & -516.17 & -192.41 & 323.76 \\
cis-trans-enol-2t & -518.92 & -199.35 & 319.57 \\
\hline
\end{tabular}

Energies in $\mathrm{kJ} / \mathrm{mol}$. 
same trend is also true for the LUMO energies. This is the outcome of the hydrogen bonding in series- 2 structures. As the carbonyl group bonds to the hydrogen atom of the enol, it becomes more powerful electron attractor. Then both the HOMO and LUMO energy levels are lowered. This effect operates on the HOMO and LUMO at unequal extents. Consequently, $\Delta \varepsilon$ values of series- 2 enols are less than the corresponding values of series-1 enols.

Although, the enolization somewhat increases the extended conjugation towards the carbonyl group not involved in the tautomerism, the perturbational effects are not so pronounced or appreciably reflected to narrow the interfrontier molecular orbital energy gaps of the enols considered. Thus, $\Delta \varepsilon$ values of the enols exhibit not a great narrowing of FMO energy gaps as compared to the parent diketo isomers (see Tables 3 and 8).

\section{Conclusion}

The present treatment has revealed that trans-trans isomer (curcumin itself) is more stable than the other configurational isomers, cis-trans and cis-cis. QSAR properties of the diketo isomers are very comparable although dipole moments are quite different. Curcumin is electronically less stable than its enol form trans-trans-enol-2. Similarly, cis-trans-enol-2c and cis-trans-enol-2t are more stable than their respective diketo forms. All these enols of enol-2 series are capable of forming intramolecular hydrogen bonding with the nearby keto group.

\section{References}

[1] K.I. Priyadarsini, The chemistry of curcumin: From extraction to therapeutic agent, Molecules 19 (2014), 20091-20112. https://doi.org/10.3390/molecules191220091

[2] L.E. Wright, J.B. Frye, B. Gorti, B.N. Timmermann and J.L. Funk, Bioactivity of turmeric-derived curcuminoids and related metabolites in breast cancer, Curr. Pharm. Des. 19 (2013), 6218-6225. https://doi.org/10.2174/1381612811319340013

[3] S.J. Hewlings and D.S. Kalman, Curcumin: A review of its' effects on human health, Foods 6(10) (2017), 92/1-92/11. https://doi.org/10.3390/foods6100092

[4] B.B. Aggarwal and K.B. Harikumar, Potential therapeutic effects of curcumin, the antiinflammatory agent, against neurodegenerative, cardiovascular, pulmonary, metabolic, autoimmune and neoplastic diseases, Int. J. Biochem. Cell Biol. 41 (2009), 40-59. https://doi.org/10.1016/j.biocel.2008.06.010 
[5] B.B. Aggarwal, A. Kumar and A.C. Bharti, Anticancer potential of curcumin: Preclinical and clinical studies, Anticancer Res. 23 (2003), 363-398.

[6] P. Basnet and N.S. Basnet, Curcumin: An anti-inflammatory molecule from a curry spice on the path to cancer treatment, Molecules 16 (2011), 4567-4598.

https://doi.org/10.3390/molecules16064567

[7] A.B. Kunnumakkara, D. Bordoloi, C. Harsha, K. Banik, S.C. Gupta and B.B. Aggarwal, Curcumin mediates anticancer effects by modulating multiple cell signaling pathways, Clin. Sci. 131 (2017), 1781-1799. https://doi.org/10.1042/CS20160935

[8] Y.G. Lin, A.B. Kunnumakkara, A. Nair, W.M. Merritt, L.Y. Han, G.N.A. Pena, A.A. Kamat, W.A. Spannuth, D.M. Gershenson, S.K. Lutgendorf, B.B. Aggarwal and A.K. Sood, Curcumin inhibits tumor growth and angiogenesis in ovarian carcinoma by targeting the nuclear factor- $\kappa \mathrm{B}$ pathway, Clin. Cancer Res. 13 (2007), 3423-3430. https://doi.org/10.1158/1078-0432.CCR-06-3072

[9] G.B. Mahady, S.L. Pendland, G. Yun and Z.Z. Lu, Turmeric (Curcuma longa) and curcumin inhibit the growth of Helicobacter pylori, a group 1 carcinogen, Anticancer Res. 22 (2002), 4179-4181.

[10] Y. Panahi, M.S. Hosseini, N. Khalili, E. Naimi, L.E.S. Mendia, M. Majeed and A. Sahebkar, Effects of curcumin on serum cytokine concentrations in subjects with metabolic syndrome: A post-hoc analysis of a randomized controlled trial, Biomed. Pharmacother. 82 (2016), 578-582. https://doi.org/10.1016/j.biopha.2016.05.037

[11] H.K. Han, The effects of black pepper on the intestinal absorption and hepatic metabolism of drugs, Expert Opin. Drug Metab. Toxicol. 7 (2011), 721-729. https://doi.org/10.1517/17425255.2011.570332

[12] G. Shoba, D. Joy, T. Joseph, M. Majeed, R. Rajendran and P.S. Srinivas, Influence of piperine on the pharmacokinetics of curcumin in animals and human volunteers, Planta Med. 64 (1998), 353-356. https://doi.org/10.1055/s-2006-957450

[13] A. Marchiani, C. Rozzo, A. Fadda, G. Delogu and P. Ruzza, Curcumin and curcumin-like molecules: From spice to drugs, Curr. Med. Chem. 21 (2014), 204-222. https://doi.org/10.2174/092986732102131206115810

[14] Y. Panahi, G.H. Alishiri, S. Parvin and A. Sahebkar, Mitigation of systemic oxidative stress by curcuminoids in osteoarthritis: Results of a randomized controlled trial, J. Diet. Suppl. 13 (2016), 209-220. https://doi.org/10.3109/19390211.2015.1008611

[15] M.L. Lestari and G. Indrayanto, Curcumin, Ch.3 (39, 113-204), Profiles Drug Subst. Excip. Relat. Methodol., Amsterdam: Elsevier, 2014. https://doi.org/10.1016/B978-0-12-800173-8.00003-9 
[16] R.C. Reddy, P.G. Vatsala, V.G. Keshamouni, G. Padmanaban and P.N. Rangarajan, Curcumin for malaria therapy, Biochem. Biophys. Res. Commun. 326 (2005), 472-474. https://doi.org/10.1016/j.bbrc.2004.11.051

[17] L.V. Ramirez, P.P. Lopez, A.V. Lopez, M.R. Tortosa, M. Battino and J.L. Quiles, Curcumin and liver disease, Biofactors 39 (2013), 88-100.

https://doi.org/10.1002/biof.1057

[18] M.C. Fadus, C. Lau, J. Bikhchandani and H.T. Lynch, Curcumin: An age-old antiinflammatory and anti-neoplastic agent, Journal of Traditional and Complementary Medicine 7 (2017) 339-346. https://doi.org/10.1016/j.jtcme.2016.08.002

[19] K.I. Priyadarsini, D.K. Maity, G.H. Naik, M.S. Kumar, M.K. Unnikrishnan, J.G. Satav and H. Mohan, Role of phenolic O-H and methylene hydrogen on the free radical reactions and antioxidant activity of curcumin, Free Radic. Biol. Med. 35 (2003), 475484. https://doi.org/10.1016/s0891-5849(03)00325-3

[20] J.J.P. Stewart, Optimization of parameters for semiempirical methods I. Method, $J$. Comput. Chem. 10 (1989), 209-220. https://doi.org/10.1002/jcc.540100208

[21] J.J.P. Stewart, Optimization of parameters for semi empirical methods II. Application, $J$. Comput. Chem. 10 (1989), 221-264. https://doi.org/10.1002/jcc.540100209

[22] A.R. Leach, Molecular Modeling, Essex: Longman, 1997.

[23] P. Fletcher, Practical Methods of Optimization, New York: Wiley, 1990.

[24] W. Kohn and L. Sham, Self-consistent equations including exchange and correlation effects, J. Phys. Rev. 140 (1965), 1133-1138. https://doi.org/10.1103/PhysRev.140.A1133

[25] R.G. Parr and W. Yang, Density Functional Theory of Atoms and Molecules, London: Oxford University Press, 1989.

[26] A.D. Becke, Density-functional exchange-energy approximation with correct asymptotic behavior, Phys. Rev. A 38 (1988), 3098-3100.

https://doi.org/10.1103/PhysRevA.38.3098

[27] S.H. Vosko, L. Vilk and M. Nusair, Accurate spin-dependent electron liquid correlation energies for local spin density calculations: a critical analysis, Can. J. Phys. 58 (1980), 1200-1211. https://doi.org/10.1139/p80-159

[28] C. Lee, W. Yang and R.G. Parr, Development of the Colle-Salvetti correlation-energy formula into a functional of the electron density, Phys. Rev. B 37 (1988), 785-789. https://doi.org/10.1103/PhysRevB.37.785 
[29] SPARTAN 06, Wavefunction Inc., Irvine CA, USA, 2006.

[30] I. Fleming, Frontier Orbitals and Organic Chemical Reactions, London: Wiley, 1976. 